\title{
Abortamento criminoso, prova penal e sigilo médico: uma análise transdisciplinar
}

Abortion, criminal evidence and medical secrecy: a transdisciplinary analysis

Aborto criminal, evidencia criminal y confidencialidad médica: un análisis transdisciplinario

Suéllyn Mattos de Aragão ${ }^{1}$

\section{Resumo}

Objetivo: debater, a partir de revisão de literatura e de dispositivos normativos, conflitos éticos e paradoxos jurídicos que permeiam a tipificação adotada pela tutela penal para enquadramento do aborto criminoso, seus meios de prova produzidos pela medicina legal e o disposto no código de ética médica acerca do sigilo profissional. Metodologia: utilizou-se uma abordagem qualitativa com natureza descritiva e exploratória. Foi realizada revisão bibliográfica de artigos, normas e jurisprudência a partir de descritores pré-definidos. Resultados: a prova pericial na investigação de aborto criminoso constitui-se em ato que afronta o dispositivo do código de ética médica referente ao sigilo profissional, além de ferir a prerrogativa de autonomia dos corpos das mulheres e o preceito da não autoincriminação. Conclusões: a proteção das normas deontológicas referentes ao sigilo médico não tem sido capaz de conferir tratamento adequado a gestante nos casos de investigação de abortamento criminoso, sobretudo se considerados as bases fundamentais dos direitos reprodutivos: integridade corporal, autonomia pessoal, igualdade e diversidade.

Palavras-chave: Aborto criminoso. Prova pericial. Confidencialidade. Bioética. Direitos Humanos.

\begin{abstract}
Objective: to debate, based on a literature review and normative provisions, ethical conflicts and legal paradoxes that permeate the typification adopted by criminal tutelage for framing criminal abortion, its means of proof produced by legal medicine and the provisions of the code of medical ethics about professional secrecy. Methodology: it was used a qualitative approach with a descriptive and exploratory nature. A bibliographic review of articles, rules and jurisprudence was carried out using pre-defined descriptors. Results: expert evidence in the investigation of criminal abortion is an act that affront the device of the code of medical ethics regarding professional secrecy, in addition to hurting the autonomy prerogative of women bodies and the precept of non- self-discrimination. Conclusions: the protection of deontological norms related to medical confidentiality was not able to verify proper treatment to the pregnant in cases of investigation of criminal abortion, especially if considered as fundamental bases of reproductive rights: body integrity, personal autonomy, equality and diversity.
\end{abstract}

Keywords: Abortion criminal. Expert testimony. Confidentiality. Bioethics. Human Rights.

\footnotetext{
${ }^{1}$ Médica; mestre em Saúde Coletiva; pesquisadora associada da Clínica de Direitos Humanos (Biotecjus), Universidade Federal do Paraná; médica da Universidade Federal do Paraná e do Ministério Público Estadual do Paraná, Curitiba, Paraná, Brasil. https://orcid.org/0000-0002-4497-1621. E-mail: smdaragao@mppr.mp.br
} 


\section{Resumen}

Objetivo: debate, basado en la revisión de literatura y disposiciones normativas, conflictos éticos y paradojas legales que impregnan la tipificación adoptada por la tutela criminal para enmarcar el aborto criminal, su evidencia producida por la medicina legal y las disposiciones del código de ética médica sobre el secreto professional. Metodología: se utilizó un enfoque cualitativo de carácter descriptivo y exploratorio. Se realizó una revisión bibliográfica de artículos, normas y jurisprudencia utilizando descriptores predefinidos. Resultados: la evidencia experta en la investigación del aborto criminal es un acto que ofende la provisión del código de ética médica con respecto al secreto profesional, además de dañar la prerrogativa de autonomía de los cuerpos de las mujeres y el precepto de no discriminación. Conclusiones: la protección de las normas deontológicas con respecto a la confidencialidad médica no ha sido capaz de dar a las mujeres embarazadas un tratamiento adecuado en casos de investigación de aborto criminal, especialmente considerando las bases fundamentales de los derechos reproductivos: integridad corporal, autonomía personal, igualdad y diversidad.

Palabras clave: Aborto criminal. Testimonio de experto. Confidencialidad. Bioética. Derechos Humanos.

\section{Introdução}

Tratar do aborto significa adentrar em um campo polêmico, de disputas, que mobiliza os sentimentos mais íntimos, a consciência e as vivências das pessoas que de alguma forma estão implicadas nessa temática. Envolve as normas sociais construídas e reconstruídas ao longo de séculos e, ao mesmo tempo, conceitos científicos, filosóficos e sociológicos (1).

De forma geral, o debate jurídico central gira em torno de duas teses preestabelecidas. Por um lado, têm-se a visão de sua prática como grave infração moral, centrada na heteronomia e na sacralidade da vida; por outro, a concepção de exercício de autonomia reprodutiva das mulheres, no horizonte dos direitos humanos. Diferentes estudos brasileiros $(2,3)$ ratificam a tese de que a ilegalidade do aborto possui implicações negativas na saúde das mulheres, pouco coíbe a prática e, pior, reforça a desigualdade social, visto que o risco engendrado pela clandestinidade afeta majoritariamente as vítimas pobres e vulneráveis, que não têm acesso aos recursos médicos para o aborto seguro.

Para além das importantes discussões pertinentes ao start da concepção e da vida intrauterina, aos direitos reprodutivos, às transformações nas relações sociais de gênero, às linhas de forças de biopoderes e aos controles incidentes, exsurge um paradoxo tangencial à disputa. Precisamente situado entre a norma penal acerca da criminalização do aborto, a metodologia médico-legal de investigação desse tipo de delito e os preceitos éticos relacionados ao sigilo médico. 
Nesse contexto, o presente estudo tem como objetivo debater, a partir de revisão de literatura e de dispositivos normativos, conflitos éticos e paradoxos jurídicos que permeiam a tipificação adotada pela tutela penal para enquadramento do aborto criminoso, seus meios de prova produzidos pela medicina legal e o disposto no Código de Ética Médica (4) acerca do sigilo profissional.

\section{Metodologia}

Para o alcance do objetivo proposto utilizou-se uma abordagem qualitativa com natureza descritiva e exploratória. Foi realizada revisão bibliográfica de: a) artigos (Lilacs, Medline e Scielo); b) legislação e normativas (portal do Governo Federal ${ }^{2}$, portal do Conselho Federal de Medicina ${ }^{3}$ ) e c) jurisprudência (portal jurisprudência unificada do Conselho da Justiça Federal ${ }^{4}$ ). Para a seleção do material foram utilizados os seguintes descritores: aborto e sigilo médico, aborto e prova penal. Na consulta legislativa, especificamente, foram também buscados: aborto, vida privada, segredo profissional, sigilo profissional e comunicação de crime. A coleta de dados ocorreu no período compreendido entre agosto/2019 e setembro/2019. A partir dos descritores foram identificadas 335 referências. Dessas, 286 foram excluídas em razão de não tratarem diretamente das categorias relacionadas ao conteúdo do presente artigo, quais sejam: conceituação de aborto, tipificação penal do aborto criminoso, prova penal no aborto criminoso e interface entre os meios de prova médico-legais do aborto criminoso e os pressupostos éticos do exercício da Medicina, especialmente o sigilo médico.

Dessa maneira, o artigo foi estruturado a partir das 49 referências selecionadas, com os resultados organizados em 4 tópicos: 1) conceituação do aborto e tipificação penal no ordenamento jurídico brasileiro; 2) meio de prova do aborto criminoso, 3) sigilo médico e o abortamento criminoso; 4) problematização do conflito entre os meios de prova médicolegais do aborto criminoso e os pressupostos éticos do exercício da medicina.

\section{Resultados e discussão}

Os principais resultados encontrados na pesquisa, a partir das categorias previamente definidas, foram compilados no quadro 1.

\footnotetext{
2 Disponível em: http://www4.planalto.gov.br/legislacao/.

3 Disponível em: https://portal.cfm.org.br/index.php?option=com_normas

${ }^{4}$ Disponível em: https://www2.cjf.jus.br/jurisprudencia/unificada/.
} 
Quadro 1. Resultados da pesquisa

\begin{tabular}{|c|c|}
\hline Conteúdo & Fonte \\
\hline $\begin{array}{l}\text { Conceito de aborto e } \\
\text { tipificação penal no } \\
\text { ordenamento jurídico } \\
\text { brasileiro }\end{array}$ & $\begin{array}{l}\text { Código Penal Brasileiro, art. 124 (5): } \\
\text { Provocar aborto em si mesma ou consentir que outrem lho provoque. } \\
\text { Pena - detenção, de um a três anos. } \\
\text { De Placido e Silva (6): } \\
\text { Aborto é a de expulsão prematura do feto ou embrião antes do tempo do parto. } \\
\text { Barros (7): } \\
\text { Provocar o aborto é dar causa ou produzir a morte do produto da concepção. } \\
\text { Gomes (8): } \\
\text { Aborto é a interrupção da gravidez antes que o feto seja viável, ou seja, antes } \\
\text { que ele possa viver fora do útero. } \\
\text { Capez (9): } \\
\text { O aborto consiste na eliminação da vida intrauterina. } \\
\text { WHO (10): } \\
\text { O abortamento é a interrupção voluntária ou involuntária da gravidez antes da } 22^{a} \\
\text { semana de gestação ou antes que o concepto alcance o peso de } 500 \text { gramas. } \\
\text { Ministério da Saúde (11): } \\
\text { Abortamento é a interrupção da gravidez até a } 20^{a}-22^{a} \text { semana de gestação e } \\
\text { com o produto da concepção pesando menos de } 500 \mathrm{~g} \text {. } \\
\text { Faúndez e Barzelatto (12): } \\
\text { A diferença entre aborto e nascimento prematuro é a viabilidade. } \\
\text { Ribeiro e Spink (13): } \\
\text { A viabilidade foi estabelecida pela OMS a partir de } 20 \text { semanas completas de gestação } \\
\text { ou com um feto de } 500 \text { gramas. Assim, abaixo desse limite, o término da gestação é } \\
\text { definido como aborto, acima é considerado como parto de bebê prematuro. } \\
\text { sentimental, ético ou humanitário. } \\
\text { Classificação Internacional das Doenças (14): } \\
\text { O aborto, provocado ou não, é considerado uma entidade nosológica, está } \\
\text { contemplado nos códigos O00 a O08 da CID-10. } \\
\text { Bitencourt (15): } \\
\text { O aborto só é criminoso quando provocado. } \\
\text { Coto ou nascido vivo inadaptado. } \\
\text { Masson (16): } \\
\text { A proteção penal contra o aborto surge a partir do momento em que as células } \\
\text { germinais se fundem, com a constituição do ovo ou zigoto, até aquele em que se } \\
\text { inicia o processo de parto, pois a partir daí o crime será de homicídio ou } \\
\text { infanticídio. } \\
\text { froce (17): }\end{array}$ \\
\hline
\end{tabular}




\begin{tabular}{|c|c|}
\hline & $\begin{array}{l}\text { Torres, Figueiró, Mendes, Melo e Inaba (19): } \\
\text { A partir de } 1996 \text { os serviços públicos de saúde do Brasil normatizaram algum tipo } \\
\text { de atendimento especializado para casos de aborto. }\end{array}$ \\
\hline $\begin{array}{l}\text { Meio de prova do } \\
\text { aborto criminoso }\end{array}$ & $\begin{array}{l}\text { Gomes (8): } \\
\text { A inspeção e avaliação da cavidade vaginal, do colo do útero, da cavidade e das } \\
\text { membranas uterinas e da cavidade amniótica a procura de vestígios de } \\
\text { tamponamentos, duchas, cauterização, esponjas, dilatadores mecânicos, } \\
\text { perfurações (sondas, agulhas, varetas, palitos), curetagem, aspiração a vácuo, } \\
\text { histerectomia e injeção de líquidos, invariavelmente, são realizados por } \\
\text { profissional médico. } \\
\text { Croce e Júnior (17): } \\
\text { Em casos suspeitos de abortamento criminoso a perícia médico-legal assume } \\
\text { papel fundamental } \\
\text { Bitencourt (20): } \\
\text { Três elementos fundamentais compõem o fato típico: conduta (ação e omissão), } \\
\text { resultado (exceto na tentativa) e nexo de causalidade. } \\
\text { Perícia médico-legal (47): } \\
\text { p médico perito, ao ser nomeado, investe-se automaticamente em função } \\
\text { pública, subordinando-se às obrigações e preceitos norteadores da } \\
\text { administração pública. }\end{array}$ \\
\hline $\begin{array}{l}\text { Sigilo médico e } \\
\text { abortamento } \\
\text { criminoso }\end{array}$ & $\begin{array}{l}\text { Código de Ética Médica, art. } 73 \text { (4): } \\
\text { Revelar fato de que tenha conhecimento em virtude do exercício de sua profissão, } \\
\text { salvo por motivo justo, dever legal ou consentimento, por escrito, do paciente. } \\
\text { Parágrafo único. Permanece essa proibição: a) mesmo que o fato seja de } \\
\text { conhecimento público ou o paciente tenha falecido; b) quando de seu depoimento } \\
\text { como testemunha (nessa hipótese, o médico comparecerá perante a autoridade } \\
\text { e declarará seu impedimento); c) na investigação de suspeita de crime, o médico } \\
\text { estará impedido de revelar segredo que possa expor o paciente a processo penal } \\
\text { (grifo nosso). } \\
\text { Código Penal, art. 154 (5): } \\
\text { Revelar alguém, sem justa causa, segredo, de que tem ciência em razão de } \\
\text { função, ministério, ofício ou profissão, e cuja revelação possa produzir dano a } \\
\text { outrem. Pena - detenção, de três meses a um ano, ou multa. } \\
\text { Constituição Federal, art. } 5^{\circ} \text {, inciso X (21): } \\
\text { São invioláveis a intimidade, a vida privada, a honra e a imagem das pessoas, } \\
\text { assegurado o direito a indenização pelo dano material ou moral decorrente de } \\
\text { sua violação. } \\
\text { Cesca e Orzari (22): } \\
\text { O sigilo profissional funciona, assim, como parte da concretização da garantia } \\
\text { fundamental de tutela da intimidade e, ainda, cumpre outras relevantes funções } \\
\text { protetivas. O sigilo relacionado ao ofício da medicina foi contemporaneamente } \\
\text { associado ao princípio bioético da autonomia, vez que, pertencendo os dados } \\
\text { pessoais ao paciente, apenas ele pode decidir a quem deseja informá-los. } \\
\text { Villas-Boas (23): }\end{array}$ \\
\hline
\end{tabular}


Warembourg-Auqe (24):

O reconhecimento da posição de confidente necessário das profissões da saúde deriva da doutrina francesa, para a qual justifica-se o sigilo caso a revelação do segredo se faça para profissional indispensável socialmente e desde que o segredo esteja efetivamente relacionado ao desempenho da profissão.

\section{Loch (25):}

A primeira referência ao sigilo médico surge no Juramento de Hipócrates. Ele contém, na sua essência, os preceitos fundamentais da ética médica.

\section{Declaração Universal dos Direitos Humanos, art. XII (26):}

Existe direito a não interferência na vida pessoal ou familiar, o que se estende à questão do sigilo profissional.

\section{Código de Processo Penal, art. 207 (27):}

São proibidas de depor as pessoas que, em razão de função, ministério, ofício ou profissão, devam guardar segredo, salvo se, desobrigadas pela parte interessada, quiserem dar o seu testemunho.

Código de Processo Civil, art. 388 e art. 404 (28):

Art. $388^{\circ}$ : A parte não é obrigada a depor sobre fatos: [...] II - a cujo respeito, por estado ou profissão, deva guardar sigilo.

Art. 404: A parte e o terceiro se escusam de exibir, em juízo, o documento ou a coisa se: [...] IV - sua exibição acarretar a divulgação de fatos a cujo respeito, por estado ou profissão, devam guardar segredo.

\section{Leite e Gunther (29):}

O Código de Ética Médica brasileiro utiliza o conceito da escola doutrinária eclética que adota o critério da relativização do sigilo em face de razões de ordem social ou interesses relevantes. Há três escolas doutrinárias que cercam o sigilo médico: a absolutista, que impõe um sigilo total em todos os casos e para a qual a obrigação do segredo não é facultativa, e sim absoluta; a abolicionista que prega justamente o contrário, estranhando-se com 0 fato da lei proteger a intimidade de uma pessoa em prejuízo de interesses coletivos; e a eclética ou relativista, que adota o critério da relativização do sigilo em face de razões de ordem social ou interesses mais relevantes.

\section{França (30):}

A justa causa é o interesse de ordem moral ou social que autoriza o não cumprimento de uma norma, contanto que os motivos apresentados sejam relevantes ao bem comum para justificar tal violação.

\section{Brasil (31,32):}

Dever legal é toda quebra do segredo por obediência ao que está regulado em lei. Poucas são as situações apontadas na norma, por exemplo, a notificação compulsória de doenças transmissíveis, tal qual está disciplinada na Lei $n^{\circ} 6.259$, de 30 de outubro de 1975. Outros exemplos seriam a suspeita de maus-tratos contra criança ou adolescente, atestado de óbito e as obrigações inerentes à condição de médico perito.

\section{Julgados $(33,34)$ e pronunciamentos do Conselho de Classe de Medicina $(35,36,37)$ : \\ O médico assistente está impedido de revelar segredo que exponha o paciente a processo criminal. Inobstante, em alguns casos, as normativas dos órgãos de classe sugerem que, em caso de investigação criminal, o conteúdo dos}




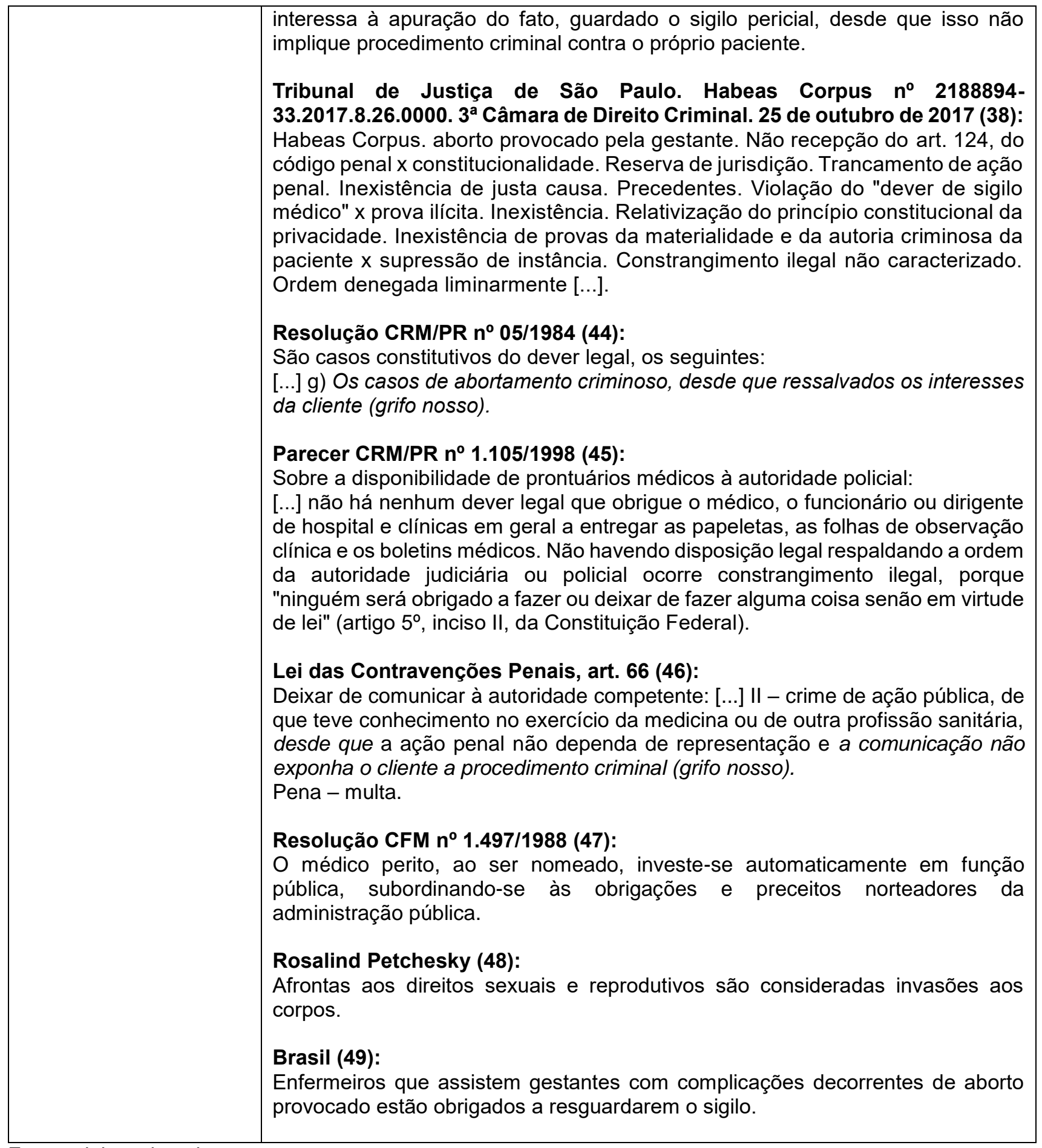

Fonte: elaborado pela autora.

\section{Conceituação do aborto e tipificação penal no ordenamento jurídico brasileiro}

Etimologicamente o vernáculo aborto é de origem latina, decompõe-se em $a b$ (privação) e ortus (nascimento). A definição proposta por De Placido e Silva (6) em seu vocabulário jurídico é a de expulsão prematura do feto ou embrião antes do tempo do parto. 
Diferentes conceituações para o aborto têm sido formuladas pela doutrina penal e pela medicina legal. Conforme os ensinamentos de Barros (7), provocar o aborto seria dar causa ou produzir a morte do produto da concepção.

De acordo com Hélio Gomes (8), o aborto é a interrupção da gravidez antes que o feto seja viável, ou seja, antes que ele possa viver fora do útero. É a interrupção da prenhez, com a morte do produto, haja ou não expulsão, qualquer que seja seu estado evolutivo, desde a concepção até momentos antes do parto.

Capez (9), assim define:

O aborto consiste na eliminação da vida intrauterina. Não faz parte do conceito de aborto a posterior expulsão do feto, pois pode ocorrer que o embrião seja dissolvido e depois reabsorvido pelo organismo materno em virtude de um processo de autólise, ou então pode suceder que ele sofra processo de mumificação ou maceração, de modo que continue no útero materno (9).

A Organização Mundial de Saúde (10) assevera que o abortamento é a interrupção voluntária ou não da gravidez antes de atingida a viabilidade fetal (22 semanas ou 500 gramas). No Brasil, o Ministério da Saúde (11) adota definição assemelhada: "abortamento é a interrupção da gravidez até a $20^{\underline{a}}-22^{a}$ semana de gestação e com o produto da concepção pesando menos de $500 \mathrm{~g}$; aborto é o produto da concepção eliminado no abortamento".

Segundo Faúndez e Barzelatto (12), traduzir aborto simplesmente como a interrupção da gestação é inadequado. Como dito, a diferença entre aborto e nascimento prematuro é a viabilidade, o que significa entender o abortamento induzido como a interrupção da gestação pelo uso de drogas ou intervenção cirúrgica após a implantação do concepto e antes que o produto da concepção tenha se tornado viável. A viabilidade foi estabelecida pela OMS a partir de 20 semanas completas de gestação ou com um feto de 500 gramas. Assim, abaixo desse limite, o término da gestação é definido como aborto, acima é considerado como parto de bebê prematuro (13).

Conforme a Classificação Internacional das Doenças (CID), o aborto, provocado ou não, é considerado uma entidade nosológica, está contemplado nos códigos 000 a 008 da CID-10 (14).

A partir da conceituação do termo, procedente a inferência de que a definição de aborto está intimamente relacionada ao universo médico, sobretudo no que se refere ao 
diagnóstico e a produção da prova técnica. As definições de idade gestacional e peso fetal, fundamentais nessa determinação, apontam nesse sentido. Como se demonstrará nos próximos tópicos, a constatação do delito do aborto, sua causa provável e suas implicações estão a cargo de profissionais médicos. Esse pressuposto é a base do raciocínio desenvolvido no presente estudo e será essencial a argumentação de sustentação.

O presente artigo volta-se, especialmente, ao debate relativo ao aborto provocado, considerado crime pelo ordenamento jurídico brasileiro.

Nas palavras de Bitencourt (15) o aborto só é criminoso quando provocado, pois possui a finalidade de interromper a gravidez e eliminar o produto da concepção, sendo exercido sobre a gestante ou sobre o próprio feto ou embrião.

O Código Penal brasileiro de 1940 (5) deixa de punir o aborto apenas quando realizado sob certas circunstâncias: estupro ou perigo de morte para a gestante. Salvo essas situações, o aborto é penalizado. Essa é a regra vigente na atualidade.

Para tipificar o crime de aborto, o Código Penal adotou a teoria concepcionista, segundo a qual a vida humana começa a existir a partir da fecundação. Assim, à luz da dogmática penal, há aborto qualquer que seja a fase da evolução fetal. Nesse caso, a proteção penal surge a partir do momento em que as células germinais se fundem, com a constituição do ovo ou zigoto, até aquele em que se inicia o processo de parto, pois a partir daí o crime será de homicídio ou infanticídio (16).

Segundo Croce e Júnior (17), trata-se de delito material de dano efetivo cujo momento consumativo ocorre com a morte do produto da concepção, seja ovo, embrião, feto ou nascido vivo inadaptado. Admite-se a tentativa quando, a despeito do abortamento, 0 concepto não morre por circunstâncias alheias à vontade do executor (art. 14, II, do CP).

Segundo consta dos dispositivos previstos no Código Penal, têm-se seis formas de aborto, diferenciadas pela natureza do agente e pelo consentimento da gestante: a) aborto provocado pela própria gestante, ou autoaborto (art. 124, primeira parte); b) aborto com consentimento da gestante para que outrem lhe provoque o abortamento (art. 124, segunda parte); c) aborto provocado sem o consentimento da gestante. Este não consentimento pode decorrer de violência, ameaça, fraude (art. 125), ou de certas condições que façam presumir a incapacidade da gestante para consentir (art. 126, parágrafo único); d) aborto consentido ou consensual (art. 126); e) aborto qualificado, pela lesão grave ou morte da gestante (art. 
127); f) aborto permitido, nos casos do art. 128, I e II, do CP. No caso de estupro (art. 128, II, do CP), temos o chamado aborto moral, sentimental, ético ou humanitário (18).

Ocorre que tais hipóteses, bem delineadas no plano teórico, subsistem, na prática do mundo jurídico e da dinâmica dos serviços de saúde, de maneira não ordenada e não regulamentada. Por vezes, carregadas de vieses interpretativos, dúvidas, vazios de fluxos e dificuldades que acabam por atingir justamente o sujeito mais fragilizado de todo contexto: a gestante.

Tanto assim que, inobstante a vontade do legislador registrada em 1940, somente a partir de 1996 os serviços públicos de saúde do Brasil normatizaram algum tipo de atendimento especializado para esses casos (19). Muito embora exista norma técnica publicada pelo Ministério da Saúde orientando acerca da desejável atenção humanizada ao abortamento (19), na prática, em muitos serviços públicos e privados do país, especialmente os não especializados, esse fluxo ainda não foi formalizado em protocolos ou procedimentos operacionais.

Além disso, como se demonstrará adiante, o vigente Código Penal não acompanhou a evolução dos códigos de ética médica. Isso possui impacto importante mormente quanto aos preceitos éticos contemporâneos da medicina, entre os quais, o princípio do sigilo médico. Justamente nesse ponto se encontra o paradoxo técnico jurídico que será abordado: o aparente contrassenso entre a letra penal, sua repercussão na produção da prova penal e os instrumentos normativos que guiam o sigilo médico profissional. A partir dos tópicos seguintes esse contrassenso se mostrará manifesto.

\section{Meio de prova do aborto criminoso}

O meio de prova mais adequado tecnicamente na investigação do aborto se constitui na perícia médico-legal.

De acordo com a doutrina, três elementos fundamentais compõem o fato típico: conduta (ação e omissão), resultado (exceto na tentativa) e nexo de causalidade (20). No caso do aborto, em maior ou menor medida, as três unidades guardam franca ligação com a seara médica. Isso porque a própria metodologia médico-legal e o universo que engloba o estado fisiológico da gravidez e a morte do produto da concepção resultam, indiscutivelmente, da apreciação e do diagnóstico médico. 
Seja no âmbito das instituições de saúde, das delegacias de polícia, dos institutos médico legais, dos núcleos técnicos de apoio ao Judiciário e ao Ministério Público ou em instâncias correlatas, as dúvidas da investigação relacionada ao aborto criminoso recaem sobre a conduta (ação ou omissão que gerou o aborto), o resultado (óbito do feto) e o correspondente nexo de causalidade (elo entre a ação ou omissão e a morte fetal).

As diligências na busca pela tipicidade e materialidade desse espécime de delito, interligam-se à prerrogativa médica de atestar o diagnóstico de vida (gravidez), de morte (causa mortis do aborto) e de nexo causal (elo entre ação/omissão e a norte). Raras as investigações de crime de aborto que prescindem dos conhecimentos da medicina e, particularmente, da obstetrícia forense.

Notório que em casos suspeitos de abortamento criminoso a perícia médico-legal assume papel fundamental. Na apuração das evidências do aborto provocado, busca-se: a) comprovação da gravidez: testes laboratoriais e necrópsia do útero; b) comprovação da existência de aborto: microbiópsia da mucosa uterina para detectar vilosidades coriais, testes biológicos e histopatologia dos restos ovulares e membranosos, exame do corpo lúteo ovariano, das lesões e modificações uterinas e da presença de embolia das células trofoblásticas em vasos do pulmão, restos de membrana, cicatrizes e de fúrcula e períneo, estudo do útero e dos ovários; c) exclusão da origem patológica ou acidental: patologia da gravidez, patologia materna, traumas físicos e psíquicos, d) comprovação de que foi provocado: evolução (dores, hemorragias, expulsão e evolução clínica), lesões maternas (lesões mecânicas, químicas e físicas), e) comprovação do mecanismo causador: presença do meio provocador ou das suas lesões específicas; f) exame dos restos fetais: lesões vitais ou post mortem; g) exame do instrumento suspeito; h) comprovação da presença de vilosidades coriais (17).

A inspeção e avaliação da cavidade vaginal, do colo do útero, da cavidade e das membranas uterinas e da cavidade amniótica a procura de vestígios de tamponamentos, duchas, cauterização, esponjas, dilatadores mecânicos, perfurações (sondas, agulhas, varetas, palitos), curetagem, aspiração a vácuo, histerectomia e injeção de líquidos, invariavelmente, são realizados por profissional médico (8).

Note-se que todo ciclo técnico probatório (conduta, resultado e nexo) encontra parâmetros nos fundamentos da medicina e da medicina legal. Há um inegável grau de especificidade e tecnicidade em tais elementos. Toda narrativa da produção de prova do 
aborto criminoso situa-se dentro dessa racionalidade. São necessários conhecimentos médicos próprios e singulares de anatomia, fisiologia, patologia, obstetrícia, farmacologia e medicina legal para que se produza o conjunto probatório adequado à finalidade a que se propõe: investigar o aborto em suspeita. A atividade médico-pericial está regulamentada pela Resolução CFM no 1.497/1988 (47) que estabelece que o perito nomeado pelo juízo se subordina às obrigações e preceitos norteadores da administração pública.

Assim, a prova pericial do aborto provocado é processo delicado e complexo que engloba uma investigação sistematizada e envolve conhecimentos técnicos aprofundados. Resvala, à exceção dos casos em que a autoridade policial e/ou o juízo prescindem da prova pericial, no universo do ato médico, o qual carrega em sua essência todos os princípios bioéticos de beneficência e não maleficência, incluído a preservação do sigilo profissional.

Partindo, então, do pressuposto da manifesta conexão entre o diagnóstico médico e a prova técnica da investigação do crime de aborto, o presente artigo abordará, justamente, o contraste entre a prova pericial no aborto criminoso e a prerrogativa do sigilo profissional médico, paradoxo cercado pelo universo ético, pela autonomia dos pacientes, pela preservação da cidadania e dos direitos reprodutivos.

\section{Sigilo médico e o abortamento criminoso}

A inviolabilidade da intimidade possui, no Brasil, status de garantia fundamental da pessoa humana, como preceitua o art. 5ำ, inciso X, da Constituição da República Federativa do Brasil (21). O Estado busca propiciar efetividade a essa garantia mediante diversas normas, entre elas, a do sigilo profissional, decorrente de função, ministério, ofício ou profissão. O sigilo profissional funciona, assim, como parte da concretização da garantia fundamental de tutela da intimidade e, ainda, cumpre outras relevantes funções protetivas (22).

A confidencialidade e o respeito à privacidade constituem preceitos morais tradicionais das profissões de saúde, indicando o dever de guarda e reserva em relação aos dados de terceiro a que se tem acesso em virtude do exercício da atividade laboral. Deles depende a base de confiança que deve nortear a relação profissional-paciente (23). reconhecimento da posição de confidente necessário das profissões da saúde deriva da doutrina francesa, para a qual justifica-se o sigilo caso a revelação do segredo se faça para 
profissional indispensável socialmente e desde que o segredo esteja efetivamente relacionado ao desempenho da profissão (24).

A primeira referência ao sigilo médico surge no Juramento de Hipócrates. Ele contém, na sua essência, os preceitos fundamentais da ética médica. Evolutivamente, o conceito de sigilo e sua aplicação foram adaptados às transformações sociais e históricas. A partir dos séculos XVIII e XIX passou a se constituir em dever jurídico do profissional médico, assumindo caráter deontológico e legal (25).

Outro marco importante é a Declaração Universal dos Direitos Humanos (26). Em seu art. XII ela traz o direito a não interferência na vida pessoal ou familiar, o que se estende à questão do sigilo profissional.

No Brasil, o sigilo e a privacidade da informação são garantidos por diferentes instrumentos: a) Código Penal (5), art. 154, que define o crime de violação do segredo profissional; b) Código de Processo Penal (27), art. 207, que proíbe de depor as pessoas que, em razão de função, ministério, ofício ou profissão, devam guardar segredo, salvo se, desobrigadas pela parte interessada, quiserem dar o seu testemunho; c) Código de Processo Civil (28), art. 388, inciso II, que determina que a parte não é obrigada a depor sobre fatos a cujo respeito, por estado ou profissão, deva guardar sigilo e art. 404, inciso IV, que estabelece que a parte e o terceiro se escusam de exibir, em juízo, o documento ou a coisa se sua exibição acarretar a divulgação de fatos a cujo respeito, por estado ou profissão, devam guardar segredo.

O sigilo relacionado ao ofício da medicina foi contemporaneamente associado ao princípio bioético da autonomia, vez que, pertencendo os dados pessoais ao paciente, apenas ele pode decidir a quem deseja informá-los. O médico, como receptáculo dessas informações por força da profissão, não deve divulgá-los senão por autorização do doente ou em situações excepcionais apontadas pela ética e pelo direito, como nos casos da justa causa e do dever legal (22).

O Código de Ética Médica brasileiro utiliza o conceito da escola doutrinária eclética que adota o critério da relativização do sigilo em face de razões de ordem social ou interesses relevantes (29). O sigilo é, enfim, um dos mais importantes preceitos da medicina moderna, repousa sobre um forte apelo utilitarista: a confiança mútua desenvolvida na relação médico paciente seria a chave mestra de um vínculo saudável, amistoso e frutífero do ponto de vista clínico. 
De acordo com o artigo 73 do Código de Ética Médica brasileiro, apenas três situações relativizam o sigilo médico, compelindo ao seu desnudamento: dever legal, justa causa e consentimento por escrito do paciente. Nas demais situações, o sigilo é impositivo (4). Além disso, o mesmo art. 73, parágrafo único, alínea c, estabelece que "na investigação de suspeita de crime, o médico estará impedido de revelar segredo que possa expor o paciente a processo penal".

A justa causa seria o interesse de ordem moral ou social que autoriza o não cumprimento de uma norma, contanto que os motivos apresentados sejam relevantes ao bem comum para justificar tal violação (30).

Por outro lado, entende-se por dever legal a quebra do segredo por obediência ao que está regulado em lei. Poucas são as situações apontadas na norma, por exemplo, a notificação compulsória de doenças transmissíveis, tal qual está disciplinada na Lei n 6.259 , de 30 de outubro de 1975 (31). Outros exemplos seriam a suspeita de maus-tratos contra criança ou adolescente (32), atestado de óbito e as obrigações inerentes à condição de médico perito.

Finalmente, diz-se que não há infração por quebra do segredo médico quando isso se verifica a pedido do paciente maior e capaz, ou, caso contrário, de seus representantes legais (30).

Pode-se dizer que há três escolas doutrinárias que cercam o sigilo médico: a absolutista, que impõe um sigilo total em todos os casos e para a qual a obrigação do segredo não é facultativa, e sim absoluta; a abolicionista que prega justamente o contrário, estranhando-se com o fato da lei proteger a intimidade de uma pessoa em prejuízo de interesses coletivos; e a eclética ou relativista, que adota o critério da relativização do sigilo em face de razões de ordem social ou interesses mais relevantes (29). Esta é a adotada pelo nosso Código de Ética Médica. A corrente relativista é considerada majoritária no Brasil (29). As principais controvérsias identificadas na jurisprudência e nas normativas dos Conselhos Regionais de Medicina dizem respeito às hipóteses de relativização.

Nesse universo, alguns julgados $(33,34)$ e pronunciamentos dos Conselhos de Classe $(35,36,37)$ têm reiterado o entendimento de que o médico assistente está impedido de revelar segredo que exponha o paciente a processo criminal. Inobstante, em alguns casos, as normativas dos órgãos de classe sugerem que, em caso de investigação criminal, o conteúdo dos prontuários seja disponibilizado à apreciação do perito médico nomeado pelo 
juízo. Nessas situações, de todo modo, a informação médica é exposta (quebra de sigilo), ainda que de forma indireta, via documentação (prontuário revelado ao médico perito).

Outras sentenças $(38,39)$, todavia, rechaçam, por completo, a hipótese de alegação de prova ilícita caso derivada de quebra de sigilo médico, admitindo, portanto, a plena relativização do sigilo.

Nessa perspectiva surgiram, nas últimas décadas, algumas propostas legislativas com conteúdo de vigilância dos corpos e da vida reprodutiva das mulheres - leia-se enrijecimento das normas que buscam coibir a prática do aborto. É o caso do projeto de lei de no 4.880/2016 (40), apresentado pelo deputado Rômulo Gouveia, que acrescenta dispositivo à Lei no 8.069, de 13 de julho de 1990, para tornar obrigatória a comunicação, pelos estabelecimentos de saúde, de aborto ou de sua tentativa. Outras iniciativas apresentaram conteúdo assemelhado: Proposta de Emenda à Constituição no 29/2015 (41), Projeto de Lei no 5.069/2013 (42) e Projeto de Lei Estadual/RJ no 1.316/2015 (43). Até o momento, nenhuma delas prosperou.

Voltando às definições acerca dos casos constitutivos do dever legal e da justa causa, alguns Conselhos Regionais definiram seu próprio rol de cenários que se enquadram nessas modalidades. É o caso da Resolução no 05/1984 (44), do Conselho Regional de Medicina do Paraná, que fixa que são casos constitutivos do dever legal (quebra do sigilo) as situações de abortamento criminoso, desde que ressalvados os interesses do cliente.

Ora, cabe-nos aqui uma primeira interpelação. De que forma isso seria possível? Como registrar em laudo ou prontuário médico um caso de suspeita de abortamento provocado e/ou remetê-lo à autoridade policial/forense interessada, ressalvando os interesses da paciente? Isto é, como fornecer a informação técnica (quebrando o sigilo) e, ao mesmo tempo, ressalvar o interesse da mulher (de não responder a processo penal)? Nesse contexto, traga-se à discussão o artigo 73 do Código de Ética Médica, que estabelece que "na investigação de suspeita de crime, o médico estará impedido de revelar segredo que possa expor o paciente a processo penal” (5). Note-se, segundo o Código de Ética, o médico, figura central na investigação dos casos de aborto, está impedido de revelar segredo de qualquer natureza que exponha o paciente a processo criminal. Ou seja, a Resolução CRM/PR nº 05/1984 permanece vigente e possui conteúdo conflitante com o do atual Código de Ética Médica. Além disso, a aludida resolução apresenta redação dúbia e extemporânea aos motes bioéticos contemporâneos. 
A partir de tais ponderações verifica-se que há, com efeito, indicativo de controversas jurídicas a respeito da questão do sigilo médico em casos de abortamento. Exatamente nesse espaço pretende contribuir a reflexão aqui proposta.

\section{Problematização do conflito entre os meios de prova médico-legais do aborto criminoso e os pressupostos éticos do exercício da Medicina}

Antiga a discussão em torno da possibilidade e da moralidade da quebra do sigilo médico para atender a requerimentos de autoridades constituídas e instituições, públicas e privadas, sejam eles pedidos de vistas de fichas clínicas ou de realização de exame pericial. No caso do aborto criminoso, consistentes em situações em que as figuras do delegado de polícia, promotor de justiça, advogado, perito ou representante securitário requisitam ou perscrutam, em algum momento da investigação, informações clínicas, produção de laudos periciais ou acesso a prontuários. No mais das vezes, deparam-se com a legítima resistência da categoria médica em fazê-lo, posto que, como mencionado, o sigilo profissional é um dos postulados de maior valor. Há, inclusive, no âmbito de alguns conselhos regionais de medicina, o entendimento de que não há nenhum dever legal que obrigue o médico, o funcionário ou o dirigente de hospital ou clínica a entregar registros médicos à autoridade policial (45).

$\mathrm{Na}$ atualidade, persistem controversas normativas e bioéticas importantes acerca das hipóteses de relativização do sigilo médico nos casos de abortamento criminoso. Um primeiro exemplo provém da já mencionada Resolução CRM/PR no 05/1984 que expressa que são casos constitutivos do dever legal, portanto de quebra do sigilo, as situações de abortamento criminoso, desde que ressalvados os interesses do cliente. Outro exemplo diz respeito à Lei de Contravenções Penais (46) que aduz, em seu art. 66, que se deve comunicar à autoridade competente crime de ação pública de que se tenha conhecimento no exercício da medicina, desde que a comunicação não exponha o cliente a procedimento criminal. Também no Processo Consulta CFM nำ1.973/2000 há divergência quando se determina que o fornecimento de documentos de pacientes a delegados de polícia, promotores e juízes é viável desde que não haja possibilidade de instauração de procedimento criminal contra o paciente, acrescentando que, em se tratando de possível delito de ação pública, pode-se colocar o prontuário à disposição de perito médico legal nomeado para que examine o seu conteúdo, desde que isso não implique procedimento 
criminal contra o próprio paciente. Em outras palavras, esses dispositivos respaldam a quebra do sigilo médico em casos de suspeita de abortamento criminoso, fazendo-o com a ressalva de que a violação do sigilo não exponha a paciente a processo criminal. Ocorre que essa possibilidade (quebrar o sigilo e não expor a gestante a denúncia criminal) é limitada/restrita, vez que, em muitos casos, a partir das violações do sigilo se está a instruir, justamente, uma investigação de crime de aborto.

Assim, ante as reflexões aqui propostas, exsurge o inevitável dilema ético: médicos, sejam eles assistentes, emergencistas, auditores, legistas ou peritos, independente da atividade ou prerrogativa funcional, não estão, todos, submetidos ao art. 73, parágrafo único, alínea c, do Código de Ética Médica (4)? Nos casos de aborto criminoso, o dever legal não resta afastado pela necessidade de preservação do interesse da própria examinada, no caso, de não responder a processo criminal (4)?

No caso particular dos médicos peritos, a Resolução CFM nำ 1.497/1988 (47) considera que "o médico perito, ao ser nomeado, investe-se automaticamente em função pública, subordinando-se às obrigações e preceitos norteadores da administração pública", hipótese que caracterizaria o dever legal para fins de quebra do sigilo médico. Todavia, essa prerrogativa de função pública e de cumprimento do dever legal parece não alterar o resultado final nos casos de quebra de sigilo no aborto criminoso. Do ponto de vista fático, ainda que o médico assistente apenas apresente o prontuário contendo o registro de suspeita/indício de aborto provocado ao perito do juízo e ainda que o perito médico-legal mantenha suas observações adstritas ao laudo (a ser remetido à autoridade policial/forense), ao final, o que há é a afronta ao sigilo do corpo da paciente viabilizando sua incriminação. Uma expressão do que Rosalind Petchesky (48), estudiosa dos direitos sexuais e reprodutivos, chama de "invasão dos corpos". Ou seja, o corpo da mulher é, em última instância, utilizado para produzir material que servirá de prova para incriminá-la. Enfim, sob a ótica pragmática, seja pela via direta (exame físico pericial) ou indireta (análise de prontuários e laudos), o desfecho final pode ser de exposição da gestante a processo criminal, situação vedada pelo Código de Ética Médica (art. 73, alínea c). Justamente da problematização dessa questão, entre o dever de sigilo médico e as etapas da investigação penal nos casos de aborto criminoso (incluindo o dever legal do perito), cuida o presente artigo. 
Outrossim, como médicos e enfermeiros (49) que assistem gestantes com complicações decorrentes de aborto provocado estão obrigados a resguardarem o sigilo (se assim não o fizerem respondem ética, civil e criminalmente), mais uma objeção prática surge. Quem seriam então os eventuais denunciantes do crime de aborto e, principalmente, quais elementos de legitimidade carregariam tais denúncias, considerando-se que, como apontado, o aborto é um diagnóstico substancialmente médico? Tenha-se presente que os sistemas de saúde e os profissionais médicos são os primeiros, e muitas vezes únicos, contactuantes das gestantes em abortamento. De onde, então, espera-se que partam denúncias e investigações dessa espécie? Da família e dos contatos da paciente, dela própria ou dos estabelecimentos que praticam os procedimentos abortivos de forma ilícita? Parece pouco crível. Nesse sentido, mais uma perquirição se faz pertinente. Seria o dispositivo do Código Penal que criminaliza o aborto, além de questionável sob o enfoque dos direitos sexuais reprodutivos, de certo modo inepto à finalidade a que se propõe?

\section{Conclusão}

A criminalização do aborto no Brasil e o debate em torno da justiça e dos direitos reprodutivos carregam em si uma série de temas e valores que são fundamentais para o desenvolvimento da vida das mulheres em sociedades democráticas e a solidificação da cidadania.

Paralelamente às relevantes discussões acerca da saúde pública, da liberdade, da justiça, dos direitos de integridade física das mulheres e da autonomia dos sujeitos que têm sido fomentadas pela comunidade acadêmica e pelas organizações de defesa humanitária, há uma interessante disputa ética relativa à investigação pericial do aborto criminoso que merece ser refletida.

Debilitadas, fragilizadas, em vulnerabilidade social, sem ter a quem apelar, gestantes se aventuram em clínicas e estabelecimentos clandestinos para a prática do aborto inseguro. $\mathrm{Na}$ maioria dos casos, se submetem à prática no absoluto anonimato, de modo furtivo inclusive dos familiares. Diante principalmente de complicações (sangramentos, infecções, inflamações, sepse, intoxicações, perfurações de vísceras, embolia gasosa, gangrena uterina, tétano, embolia pulmonar), recorrem aos serviços de saúde na tentativa de salvaguardar a vida e/ou evitar sequelas. 
Nesse momento, por diversas circunstâncias, como denúncias de profissionais de saúde (32) ou denúncias anônimas, acabam acusadas à autoridade policial, com fulcro no art. 124 do Código Penal. Durante a investigação criminal, comumente, a autoridade responsável requisita apoio técnico a médicos assistentes, legistas ou afins para que seja caracterizado, do ponto de vista material, a consumação do aborto (gravidez, morte do concepto, nexo de causalidade).

Com esse norte, o artigo teve como objetivo apresentar uma reflexão fundamentada acerca dos conflitos éticos e paradoxos jurídicos existentes entre os elementos de tipicidade da tutela penal para enquadramento do aborto criminoso, seus meios de prova empreendidos pela medicina legal e o disposto no Código de Ética Médica acerca do sigilo profissional.

$\mathrm{Na}$ compilação dos resultados verificou-se que no Brasil a corrente doutrinária majoritária sobre o sigilo médico é relativista, a qual autoriza, sob a égide do cumprimento do dever legal (caso dos peritos médicos), a invasão do corpo da mulher, direta (exame pericial) ou indiretamente (acesso a prontuário/laudos), em busca da verdade pericial nos casos de investigação de abortamento criminoso. Ponderamos, contudo, que, de acordo com as normas vigentes, ainda que por acesso indireto, as confidências médicas têm sido levadas ao conhecimento da autoridade investigadora e esse é um ponto que merece ser debatido sob o aspecto bioético.

O debate central apresentado pelo artigo fundamentou-se na contraposição entre o excerto do Código de Ética Médica, que determina que, na investigação de suspeita de crime o médico estará impedido de revelar segredo que possa expor o paciente a processo penal e o ato médico praticado da produção de prova do aborto (perícia médica).

$\mathrm{Na}$ discussão, também foram apontadas outras aparentes contradições normativas sobre a matéria, como é o caso de dispositivos que respaldam a quebra do sigilo médico em casos de suspeita de abortamento criminoso, fazendo-o com a ressalva de que a violação do sigilo não exponha a paciente a processo criminal. É um paradoxo pois, em muitos casos, a quebra do sigilo se dá justamente com o intuito de investigar a suspeita de crime, isto é, ao final da cadeia de eventos na investigação do aborto criminoso o que se busca é definir se há ou não provas suficientes para indiciamento da gestante, com fulcro no art. 124 do Código Penal (crime de aborto). 
A partir das reflexões expostas, infere-se que há, de fato, certo conflito ético e paradoxo jurídico entre a tipificação penal do aborto, as metodologias da medicina legal para sua caracterização (justapostas ao ato médico de diagnose e de estabelecimento do nexo causal) e o disposto no Código de Ética Médica e nas normativas dos conselhos de classe de medicina (que vedam a revelação de segredo que possa expor paciente a processo penal). Além disso, há controversas normativas quanto às possibilidades de relativização do sigilo médico em casos de abortamento (paradoxo entre quebra de sigilo e não exposição da paciente a processo criminal). Da forma com que os diferentes regramentos estão dispostos (ausência de consenso em determinados pontos), a proteção deontológica não confere tratamento adequado à gestante, sobretudo se consideradas as bases fundamentais dos direitos reprodutivos: integridade corporal, autonomia pessoal, igualdade e diversidade.

Por fim, é possível dizer que, para além da polêmica central envolvida na (des) criminalização do aborto, há essa lacuna bioética importante a ser repensada. Vazio que até o momento não recebeu atenção doutrinária e jurisprudencial capaz de elevar os debates às camadas mais profundas de argumentação, tal como o mérito da matéria exige. Indicamos aqui alguns pontos em que os dispositivos normativos vigentes parecem não contribuir para uma solução contemporânea, uníssona e razoável do problema.

\section{Referências}

1. Roseira MB. Prefácio. In: Galeotti G. História do aborto. Lisboa: Edições 70, 2007. p. 720.

2. Diniz D. Aborto e saúde pública no Brasil. Cadernos de Saúde Pública, Rio de Janeiro. 2007, 23 (9): 1992-1993.

3. Diniz D, Medeiros M. Aborto no Brasil: uma pesquisa domiciliar com técnica de urna. Ciência \& Saúde Coletiva, Rio de Janeiro. 2010; 15: 959-966.

4. Brasil. Conselho Federal de Medicina. Resolução n 2.217, de 27 de setembro de 2018. Código de Ética Médica. Brasília, 1 nov 2018. Disponível em:

https://sistemas.cfm.org.br/normas/visualizar/resolucoes/BR/2018/2217. [Acesso em: 07 de outubro de 2019].

5. Brasil. Decreto-Lei no 2.848, de 7 de dezembro de 1940. Código Penal. Disponível em: http://www.planalto.gov.br/ccivil_03/decreto-lei/del2848compilado.htm. [Acesso em: 17 de outubro de 2019].

6. De Placido e Silva OJ. Vocabulário Jurídico. 32 ed. Rio de Janeiro: Forense; 2016. 
7. Barros FAM. Direito Penal: Parte Especial: crimes contra a pessoa, crimes contra o patrimônio. $2^{a}$ ed. São Paulo: Saraiva; 2009.

8. Gomes H. Medicina legal. Rio de Janeiro: Freitas Bastos; 2004.

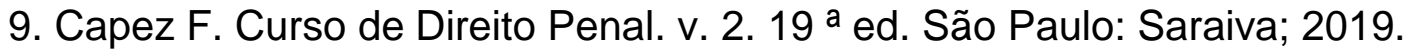

10. World Health Organization. Unsafe abortion: global and regional estimates of the incidence of unsafe abortion and associated mortality in 2008 [Internet]. Geneva: World Health Organization; 2011. Disponível em:

http://whqlibdoc.who.int/publications/2011/9789241501118_eng.pdf. [Acesso em: 15 de abril de 2020].

11. Brasil. Ministério da Saúde. Atenção Humanizada ao abortamento. Norma Técnica. 2a ed. Brasília, 2011. Disponível em:

http://bvsms.saude.gov.br/bvs/publicacoes/atencao_humanizada_abortamento_norma_tec nica_2ed.pdf. [Acesso em: 16 de outubro de 2019].

12. Faúndes A, Barzelatto J. O drama do aborto: em busca de um consenso. Campinas, SP: Komedi; 2004.

13. Ribeiro FRG, Spink MJP. Repertórios interpretativos na controvérsia sobre a legalização do aborto de fetos anencefálicos. Psicologia \& Sociedade, 2011; 23: 63-71.

14. World Health Organization. Classificação Estatística Internacional de Doenças e Problemas Relacionados à Saúde - CID-10. Disponível em https://icd.who.int/browse10/2019/en. [Acesso em: 15 de abril de 2020].

15. Bitencourt CR. Tratado de direito penal, volume 2: parte especial. 19a ed. revista e atualizada. São Paulo: Saraiva; 2019.

16. Masson C. Direito penal esquematizado. São Paulo: Método; 2011.

17. Croce D, Júnior DC. Manual de Medicina Legal. 7. ed. rev. São Paulo: Saraiva; 2010.

18. Abrahão PJ. A perícia no aborto criminoso. Conteúdo Jurídico, 2014. Disponível em: https://conteudojuridico.com.br/consulta/artigos/41677/a-pericia-no-aborto-criminoso. [Acesso em: 06 out 2019].

19. Torres ACPLGC, Figueiró MND, Mendes PP, Melo SMM, Inaba CM. Aborto no Brasil: argumentos a favor e contra a sua proposta de descriminalização. Anais do III Simpósio Internacional de Educação Sexual. 2013; 3: 1-17. Disponível em:

http://www.sies.uem.br/anais/pdf/direito_e_sexualidade/2-01.pdf. [Acesso em 21 de outubro de 2019].

20. Bitencourt CR. Tratado de direito penal: parte geral. 25a. ed. São Paulo: Saraiva, 2019. 
21. Brasil. Constituição da República Federal do Brasil. Brasília, DF: Senado Federal, 1988. Disponível em: http://www.planalto.gov.br/ccivil_03/constituicao/constituicao.htm. [Acesso em: 15 de abril de 2020].

22. Cesca BG, Orzari OAS. Prova Penal e Segredo Profissional. Revista da Faculdade de Direito da Universidade de São Paulo. 2016; 111: 555-586. Disponível em: http://www.revistas.usp.br/rfdusp/article/view/133529. [Acesso em: 31 de março de 2020].

23. Villas-Boas ME. O direito-dever de sigilo na proteção ao paciente. Revista Bioética. Brasília, 2015; 23 (3):513-523. Disponível em:

http://www.scielo.br/scielo.php?script=sci_arttext\&pid=S1983

80422015000300513\&lng=en\&nrm=iso >. [Acesso em: 12 de outubro de 2019].

24. Warembourg-Auqe F. Réflexions sur le secret professionnel. Revue de Science Criminelle et de Droit Pénal Comparé, Paris, 1978; 2: 241. Disponível em:

http://data.decalog.net/enap1/Liens/fonds/REVUE_SCIENCE_CRIMINELLE_1_1986.pdf. [Acesso em: 31 de março de 2020].

25. Loch JA. Confidencialidade: natureza, características e limitações no contexto da relação clínica. Bioética. 2003;11(1):51-64. Disponível em:

http://revistabioetica.cfm.org.br/index.php/revista_bioetica/article/view/149. [Acesso em: 31 de março de 2020].

26. Organização das Nações Unidas. Resolução 217 A (III), de 10 de dezembro de 1948. Declaração Universal dos Direitos Humanos. ONU. Disponível em:

https://nacoesunidas.org/wp-content/uploads/2018/10/DUDH.pdf. [Acesso em: 21 de outubro de 2019].

27. Brasil. Decreto-Lei no 3.689, de 03 de outubro de 1941. Código de Processo Penal. Disponível em: http://www.planalto.gov.br/ccivil_03/decreto-lei/del3689compilado.htm. [Acesso em: 17 de outubro de 2019].

28. Brasil. Lei no 13.105, de 16 de março de 2015. Código de Processo Civil. Disponível em: http://www.planalto.gov.br/ccivil_03/_ato2015-2018/2015/lei//13105.htm. [Acesso em: 09 de outubro de 2019].

29. Leite FBC, Gunther LE. A relativização do sigilo profissional médico. Revista eletrônica do Tribunal Regional do Trabalho da 9a Região. 2013, 3 (25): 24-33. Disponível em:

https://ead.trt9.jus.br/moodle/pluginfile.php/33329/mod_resource/content $/ 1 /$ Revista\%20Elet r\%C3\%B4nica\%20\%28JAN\%202017\%20-\%20n\%C2\%BA\%2056\%20-

$\% 20 \%$ C3\%8Dndice\%29.pdf. [Acesso em: 31 de março de 2020].

30. França GV. O Segredo Médico e nova ordem bioética, 2000. Disponível em: https://social.stoa.usp.br/articles/0015/4649/Texto_2_-

_O_Segredo_MA_dico_e_nova_ordem_bioA_tica.pdf. [Acesso em 20 de outubro de 2019].

31. Brasil. Lei no 6.259, de 30 de outubro de 1975. Dispõe sobre a organização das ações de Vigilância Epidemiológica, sobre o Programa Nacional de Imunizações, estabelece 
normas relativas à notificação compulsória de doenças, e dá outras providências. Disponível em: http://www.planalto.gov.br/ccivil_03/leis/L6259.htm. [Acesso em: 21 de outubro de 2019].

32. Brasil. Lei no 8.069, de 13 de julho de 1990. Estatuto da Criança e do Adolescente. Brasília, 13 jul. 1990. Disponível em: http://www.planalto.gov.br/ccivil_03/leis//8069.htm. [Acesso em: 05 de outubro de 2019].

33. Brasil. Tribunal de Justiça de São Paulo, 3aㅡ Câmara de Direito Público. Apelação Cível 1017294-93.2017.8.26.0344. Apelante: Marina Araújo Matsui. Apelada: Mireli Fernanda Belini. Relator: Maurício Fiorito. São Paulo, 13 de agosto de 2019. Disponível em: https://tjsp.jusbrasil.com.br/jurisprudencia/755067858/apelacao-civel-ac-10172949320178260344sp-1017294-9320178260344/inteiro-teor-755067878?ref=serp. [Acesso em: 31 de março de 2020].

34. Brasil. Tribunal de Justiça do Rio de Janeiro, 1a Turma Recursal Criminal. Apelação Criminal 0037981 74.2013.8.19.0205 RJ. Apelante: Marcelo Barbosa de Souza. Apelado: Ministério Público. Relator: Alessandra de Araújo Bilac Moreira Pinto. Rio de Janeiro, 30 de julho de 2015. Disponível em: https://tjrj.jusbrasil.com.br/jurisprudencia/217590053/apelacao-criminal-apr-379817420138190205rj-0037981-7420138190205?ref=serp. [Acesso em: 15 de abril de 2020].

35. Brasil. Conselho Federal de Medicina. Resolução nำ 1.605/2000. Revelação de conteúdo de prontuário ou ficha médica. Disponível em:

http://www.portalmedico.org.br/resolucoes/cfm/2000/1605_2000.htm. [Acesso em: 31 de março de 2020].

36. Brasil. Conselho Regional de Medicina/SP. Consulta n²4292/00. O segredo médico diante de uma situação de aborto. Disponível em: https://sistemas.cfm.org.br/normas/visualizar/pareceres/SP/2000/24292. [Acesso em: 31 de março de 2020].

37. Brasil. Conselho Federal de Medicina. Processo Consulta $n^{0}$ 1.973/2000. Diretor clínico - Fornecimento de documentos de pacientes a delegados de Polícia, promotores e juízes Disponível em:

https://sistemas.cfm.org.br/normas/arquivos/pareceres/BR/2000/22_2000.pdf. [Acesso em: 31 de março de 2020].

38. Brasil. Tribunal de Justiça de São Paulo. Habeas Corpus no 2188894-

33.2017.8.26.0000, Relator: Airton Vieira, 3aㅡ Câmara de Direito Criminal, Data de Publicação: 25 de outubro de 2017. Disponível em: https://tjsp.jusbrasil.com.br/jurisprudencia/517121329/21888943320178260000-sp-21888943320178260000/inteiro-teor-517121345?ref=serp. [Acesso em: 31 de março de 2020].

39. Brasil. Tribunal de Justiça de São Paulo, 16 ${ }^{\text {a }}$ Câmara de Direito Criminal. Habeas Corpus no 0296145-57.2011.8.26.0000. Relator: Alberto Mariz de Oliveira. Data da publicação: 17 de julho de 2012. Disponível em: https://tj- 
sp.jusbrasil.com.br/jurisprudencia/22132136/habeas-corpus-hc-2961455720118260000-sp0296145-5720118260000-tjsp. [Acesso em: 31 de março de 2020].

40. Brasil. Câmara dos Deputados. Projeto de Lei no 4.880/2016. Acrescenta dispositivo à Lei no 8.069, de 13 de julho de 1990. Disponível em:

https://www.camara.leg.br/proposicoesWeb/fichadetramitacao?idProposicao=2091284. [Acesso em: 31 de março de 2020].

41.Brasil. Proposta de Emenda à Constituição no 29/2015. Altera a Constituição Federal para acrescentar no art. $5^{\circ}$, a explicitação inequívoca "da inviolabilidade do direito à vida, desde a concepção. Disponível em: https://www25.senado.leg.br/web/atividade/materias//materia/120152. [Acesso em: 15 de abril de 2020].

42. Brasil. Projeto de Lei $n=5.069 / 2013$. Tipifica como crime contra a vida o anúncio de meio abortivo e prevê penas específicas para quem induz a gestante à prática de aborto. Disponível em:

https://www.camara.leg.br/proposicoesWeb/fichadetramitacao?idProposicao=565882. [Acesso em: 15 de abril de 2020].

43. Brasil. Projeto de Lei $n^{0} 1.316 / 2015$. Dispõe sobre a obrigatoriedade de comunicação imediata às autoridades policiais em caso de ocorrência de aborto na rede de saúde pública do estado do Rio de Janeiro. Disponível em:

http://alerjln1.alerj.rj.gov.br/scpro1519.nsf/1061f759d97a6b24832566ec0018d832/4b1b4fce 7c27882d83257f1f006f5700?OpenDocument. [Acesso em: 15 de abril de 2020].

44.Brasil. Conselho Regional de Medicina do Paraná. Resolução no 05/1984. Dispõe sobre casos constitutivos de dever legal e justa causa. Curitiba, 21 mai 1984. Disponível em: https://sistemas.cfm.org.br/normas/arquivos/resolucoes/PR/1984/5_1984.pdf. [Acesso em: 15 de outubro de 2019].

45. Brasil. Conselho Regional de Medicina do Paraná. Parecer № 1.105/1998. Dispõe sobre prontuário médico - cópia à autoridade policial. Disponível em:

https://sistemas.cfm.org.br/normas/visualizar/pareceres/PR/1998/1105. [Acesso em: 15 de abril de 2020].

46. Brasil. Decreto-lei no 3.668, de 03 de outubro de 1941. Lei das Contravenções Penais. Disponível em: https://www2.camara.leg.br/legin/fed/declei/1940-1949/decreto-lei-3688-3outubro-1941-413573-publicacaooriginal-1-pe.html. [Acesso em: 15 de abril de 2020].

47. Brasil. Conselho Federal de Medicina. Resolução $n^{0} 1.497 / 1988$. Dispõe sobre as atividades de médico perito. Disponível em:

https://sistemas.cfm.org.br/normas/visualizar/resolucoes/BR/1998/1497. [Acesso em: 31 de março de 2020].

48. Petchesky R. Owning and disowning the body: a reflection. In: Baksh R.; Harcourt W. The Oxford Handbook of Transnational Feminist Movements. Nova lorque: Oxford University Press, 2015. p. 252-270. Disponível em: 
https://www.oxfordhandbooks.com/view/10.1093/oxfordhb/9780199943494.001.0001/oxfor dhb-9780199943494. [Acesso em: 31 de março de 2020].

49. Brasil. Conselho Federal de Enfermagem. Relatório do seminário de debate sobre os efeitos da criminalização do aborto na saúde coletiva, 2019. Disponível em:

http://www.cofen.gov.br/relatorio-do-cofen-recomenda-humanizacao-da-assistencia-esigilo-em-casos-de-aborto_68851.html. [Acesso em: 31 de março de 2020].

\section{Como citar este artigo:}

Aragão SM. Abortamento criminoso, prova penal e sigilo médico: uma análise transdisciplinar. Cadernos IberoAmericanos de Direito Sanitário. 2020 abr./jun.; 9(2): 182-207.

http://dx.doi.org/10.17566/ciads.v9i2.591 